University of San Diego

Digital USD

Spring 5-18-2021

\title{
The Relation of Therapist Behaviors to Treatment Engagement and Outcomes in PCIT
}

Kristine Gese BA

University of San Diego

Follow this and additional works at: https://digital.sandiego.edu/honors_theses

Part of the Child Psychology Commons, Clinical Psychology Commons, and the Experimental Analysis of Behavior Commons

\section{Digital USD Citation}

Gese, Kristine BA, "The Relation of Therapist Behaviors to Treatment Engagement and Outcomes in PCIT" (2021). Undergraduate Honors Theses. 89.

https://digital.sandiego.edu/honors_theses/89

This Undergraduate Honors Thesis is brought to you for free and open access by the Theses and Dissertations at Digital USD. It has been accepted for inclusion in Undergraduate Honors Theses by an authorized administrator of Digital USD. For more information, please contact digital@sandiego.edu. 
The Relation of Therapist Behaviors to Treatment Engagement and Outcomes in PCIT

\author{
A Thesis \\ Presented to \\ The Faculty and the Honors Program \\ of the University of San Diego
}

By
Kristine Eleni Gese
Department of Psychology

2021 


\begin{abstract}
Parent Child Interaction Therapy (PCIT) has proven to be a very effective treatment for child behavioral problems, however, PCIT does not benefit all families equally, presumably at least partly because therapists may not be equally effective in coaching their clients. Although researchers have proposed several dimensions of therapist coaching behaviors that are considered desirable, few of these have been empirically examined in relation to family engagement or child outcomes. Data from two clinical trials examining the effectiveness of culturally modified versions of PCIT (GANA and PersIn), were used to investigate which of several therapist coaching behaviors (brevity, positivity, consistency, accuracy, directive coaching and responsive coaching) are related to faster parent skill acquisition, treatment retention, and child outcomes. The findings indicate that none of these skills were significant in predicting speed of parent skill acquisition or parent reported improvement in child symptoms. However, positivity and responsiveness were significant predictors of treatment completion, while therapist directiveness was significantly related to treatment dropout. These findings suggest that these three therapist behaviors are particularly important to treatment engagement for both Spanish and English speaking families and should be important targets for therapist training.
\end{abstract}




\section{Introduction}

Disruptive Behavior Disorders (DBDs), which include the diagnoses of oppositional defiant disorder (ODD), conduct disorder (CD), and attention deficit hyperactivity disorder (ADHD), are highly prevalent; $7 \%$ to $20 \%$ of school age children and adolescents, and about $13 \%$ of preschool children meet criteria for at least one of these diagnoses (Keil \& Price 2006, Ward, Theule \& Cheung 2016). DBDs are the most common reason for referral to mental health services among children, and affect close to half of children in child welfare (Bloom, Jones \& Freeman 2013, Keil et. al. 2006). These behavior disorders are overtly disruptive, including the violation of social norms, destruction of property, and aggression towards others (Keil et. al. 2006). Behavior disorders in childhood are characterized by significant impairments in social, emotional, and educational functioning (Werba, Eyberg, Boggs \& Algina, 2006). In addition to the effect DBDs have on children and their families, their special education needs, criminal justice expenses, and lost wages place a hefty burden on society (Scott, Knapp, Henderson \& Maughan, 2001). These maladaptive behavior patterns are relatively stable and will often continue or worsen as they move into adulthood if not treated (Tremblay, Masse, Perron, Leblanc, Schwartzman, 1992). Without intervention, these children are at heightened risk for later delinquency (Vogel \& Messner, 2012), substance abuse (Yoshimashu, Barbaresi, Colligan et al., 2012), school failure, antisocial personality disorder (Tremblay et al., 1992), development of comorbid disorders such as depression and anxiety (Boylan, Vaillancourt, Boyle \& Szatmari, 2007), and future disruptions in their relationships (Burke, Hipwell \& Loeber, 2010). 
There is broad consensus among researchers that early intervention is the best way to interrupt the course of DBDs and prevent these behaviors and their consequences from continuing into adulthood (Ward et. al. 2016). Parent Child Interaction Therapy (PCIT) is an efficacious treatment for child disruptive behavior disorders designed for young children that teaches parents skills to build warm relationships with their children while setting and consistently enforcing firm limits (Eyberg \& Funderburk 2011). PCIT has demonstrated efficacy in reducing child behavior problems across the DBD diagnoses in a number of randomized controlled trials. For example, a recent meta-analysis found that PCIT leads to a significantly greater reduction in child behavior problems compared with controls, with an average effect size in the large range (Ward et. al., 2016). In addition, PCIT has been proven to reduce the incidence of child abuse and neglect among parents previously referred to child protective services for child maltreatment (Chaffin et al., 2013).

Although there is strong empirical support for the efficacy of PCIT for child behavior problems, both efficacy and effectiveness trials indicate that not all families benefit equally (Werba et al., 2006, Fernandez \& Eyberg, 2009). Because PCIT is an open ended treatment that does not conclude until parents have demonstrated mastery of the skills and report child behavior problems in the normal range, drop out rates are a good indicator of both premature termination and children with continuing symptoms combined. In community effectiveness trials, drop out rates from PCIT range from 27-67\% (Boggs et al. 2005, Pearl et al. 2012, Bjørseth \& Wichstrøm 2016, Lieneman et. al. 2019), suggesting that a significant portion of families do not successfully complete treatment. Although even families who dropout of treatment prematurely show significant improvement in child behavior problems on average, with a medium to large effect 
size $(d=0.70$; Lieneman et al., 2019), there is still a sizable group of children whose symptoms are not fully resolved at termination.

Presumably, both client and therapist characteristics and behaviors contribute to the relative success of families in PCIT. A number of studies have examined the client characteristics that predict dropout and lower benefit in PCIT (e.g., Werba et. al. 2006). Demographic factors including female children, less educated parents, single parent households (Danko, Garbacz \& Budd, 2016), lower socioeconomic status, and minority status (Fernandez \& Eyberg, 2009) are predictors of poorer engagement and/or outcomes in PCIT. In addition, other contextual factors such as maternal parenting stress (Werba et. al., 2006), maternal criticism at pre-treatment (Werba et. al., 2006), maternal inappropriate behavior (Werba et. al., 2006), and low familial support for treatment (Dawson, Fain, McCabe \& Yeh, 2015), have also been found to predict dropout in PCIT. In response to the findings, a number of enhancements targeting these factors have been developed for a variety of families who have typically been less likely to enroll, engage, or benefit from PCIT, including families of ethnic minorities (McCabe \& Yeh, 2009; McCabe et al., 2020), child welfare families (Chaffin, Valle, \& Funderburk 2009), single parents of children with ADHD (Chacko, Wymbs BT, Wymbs FA, et al. 2009), and interventions designed to enhance parent motivation (Nock \& Kazdin, 2005). Thus, significant progress has been made in understanding client characteristics that predict treatment engagement and outcomes in PCIT, and enhancements targeting those characteristics have shown some promise in improving engagement and retention for populations at high risk (Chaffin, 2009, McCabe \& Yeh, 2009, Lesack et al., 2014). 
However, few studies have examined the other half of the equation, namely, how therapist behaviors impact engagement and outcomes in PCIT. One of the most important class of therapist behaviors in PCIT is its use of live coaching, which makes up approximately $2 / 3$ (30 minutes) of most sessions. Some have suggested that live coaching is responsible for PCIT's relative success in reducing child behavior problems compared with other parent training models (Barnett et. al. 2017). In support, they point to meta-analyses indicating PCIT's relatively large effect sizes compared with other BPT programs, which share similar theoretical features and content, but do not utilize live coaching (Kaminski et al. 2008). For example, Ward et. al. (2016) report an average pre- to post-treatment effect size for PCIT with ODD of 1.65, a much larger effect than is seen for other similar interventions such as the Incredible Years $(\mathrm{d}=0.50)$ or Triple P (d=0.35-0.57; Lieneman, Quetsch, Theodorou, Newton, \& McNeil, 2019, Nowak et. al 2008). The combination of modeling and social reinforcement appears to be an effective and efficient way to shift client behaviors (Traux, 1968).

Live coaching has been found to be a powerful tool for improving parenting skills; however, less is known about which specific coaching behaviors maximize parent skill acquisition and lead to reduced child behavior problems. McNeil \& Hembree-Kigin (2010) describe coaching as consisting of behaviors such as labeled praises, gentle corrections, directives, and observations of child or parent behavior that the therapist gives to either direct or respond to parent and child behavior. Further, McNeil \& Hembree-Kigin (2010) outlines a number of characteristics of coaching that are theorized to be essential to success in PCIT. For example: 1) coaching should be brief: less than five words in response to parent skill use so as not to interrupt the flow of the interaction; 2) coaching should be consistent: therapists should 
provide a response after every parent verbalization; the more input that the parent receives, the faster and better these CDI skills will be learned; 3) coaching should be positive: therapists should give 10 or more praises in a 5 minute coaching session, with at least $50 \%$ being labeled praises; this gives the parent the support needed to feel successful and reinforces the use of the CDI skills; 4) coaching should be accurate; the therapist should correctly label praise or feedback on the parent's skill use, as mistakenly labeling skills provides the parent with incorrect feedback; and 5) therapists should use more responsive coaching than directive coaching. Directive therapist verbalizations tell the parent what to do (e.g. modeling, prompting, indirect commands, direct commands, and drills), whereas responsive therapist verbalizations provide feedback and reinforce the parent's use of a skill (e.g. labeled praises, process comments, reflective descriptions, corrective criticisms, and unlabeled praises; Barnett et. al. 2014). Emphasizing responsive coaching allows the parent to independently facilitate the interaction with their child.

Although these coaching behaviors have been theorized to promote engagement and outcomes in PCIT, little research has been conducted to establish empirically which specific coaching behaviors contribute to faster skill acquisition, client engagement, and/or outcomes. Barnett, Niec \& Peer (2014) have begun to address this gap in the literature by developing a coach-coding system called the Therapist Parent Interaction Coding System (TPICS) that has allowed for the examination of the effect of a range of therapist coaching behaviors on outcomes. Barnett et al. (2014) used the TPICS to examine the relation between directive vs. responsive coaching techniques during a 10-minute sample of coaching in the first CDI coach session, and found that greater use of responsive coaching, but not directive coaching, predicted the 
frequency of positive parenting skills (i.e. praise, reflection, imitation, description, and enjoyment) in the subsequent session. In addition, they found that therapists used more responsive coaching when parents had demonstrated good use of that skill during coding. In a follow up study, Barnett et al. (2017) found that responsive coaching, but not directive coaching, was a significant predictor of speed of parent skill acquisition in the first phase of treatment as well as treatment attrition. These studies suggest that responsive coaching is a critical skill for therapists in PCIT (Barnett et. al., 2013 \& Barnett et al., 2017).

These findings have contributed greatly to our understanding of which coaching behaviors are important to parent skill acquisition and engagement. Despite this, there are still a number of potentially influential coaching techniques proposed by McNeil \& Hembree-Kigin (2010) that haven't yet been empirically examined. Barnett et al. (2014) and Barnett et al. (2017) have examined the effects of directive and responsive coaching on frequency of skill use and attrition in PCIT, addressing two of the coaching behaviors theorized to be important. In the current study, we add several codes to the TPICS that will allow us to examine the ability of four additional coaching behaviors theorized by McNeil \& Hembree-Kigin (2010) to impact treatment engagement, parent skill acquisition, and outcomes in two previously conducted clinical trials of PCIT (McCabe \& Yeh, 2009; McCabe et al. 2020). Specifically, we hypothesize that a therapist's use of brief, positive, consistent, and accurate coaching will be related to faster parent skill acquisition, treatment retention, and child outcomes. Additionally, consistent with previous studies, we predict that therapists who use more responsive coaching statements will also predict faster skill acquisition and lower attrition rates (Barnett et al., 2013 \& Barnett et al., 2017). 


\section{Methods}

\section{Participants}

Participants were 90 families who participated in two previous clinical trials evaluating culturally modified versions of PCIT: GANA ( $\mathrm{n}=58$; McCabe \& Yeh, 2009) and PersIn (n=32; McCabe et al. 2020). In both studies, families were eligible if their child met the following criteria: (1) between the ages of 2 and 7, (2) scored at or above the clinical cut-point for behavior problems on the Eyberg Child Behavior Inventory Intensity Scale (ECBI; Eyberg \& Pincus, 1999), (3) without a diagnosis of autism or intellectual disability (4) not participating simultaneously in any other psychosocial treatment for the child's behavior problems (Eyberg \& Pincus, 1999). In the GANA study, only families who identified their child as Mexican American were eligible, while in PersIn families that identified at least in part as Latinx, African American, Asian American or Non-Hispanic White (NHW) were eligible. Participants in both studies were families seeking treatment for a child with clinically significant behavior problems at a mental health clinic. The research team conducted additional outreach to the community headstarts, schools, pediatrician's offices, and social media to increase awareness of available services. Below, we describe each sample in more detail.

GANA sample. Child participants $(\mathrm{N}=58)$ ranged from 3- to 7-years of age -old $(M=$ 52.77 months, $S D=11.6$ ). About $70 \%$ of children were male, and approximately $67 \%$ of the children preferred Spanish. Approximately $76 \%$ of primary caregivers were first generation Americans, $81 \%$ of primary caregivers preferred Spanish, $68.7 \%$ of mother caregivers were married, $50.9 \%$ of mothers had an education level less than high school, and families reported an 
average household yearly income of $\$ 23,112$. All primary caregivers were female (for a full description, see McCabe \& Yeh, 2009). Participating children had an average pre-treatment ECBI Score of $179.80(S D=29.76)$. For the current study, we included only those families who completed either standard PCIT or GANA $(\mathrm{N}=40)$. Further, some families were excluded $(\mathrm{n}=20)$ because they did not have a codable CDI Coach 2 session, resulting in a final sample of $\mathrm{n}=20$ for our analyses $(\mathrm{GANA}=9$; PCIT $=11)$.

PersIn Sample. Participating families $(\mathrm{n}=32)$ were of multiple ethnicities: Latinx $(28 \%$ of children, $28 \%$ of caregivers), NHW (22\% of children, $34 \%$ of caregivers), African American ( $13 \%$ of children, $6 \%$ of caregivers), Asian American (16\% of children, $22 \%$ of caregivers), and multiethnic ( $22 \%$ of children, $9 \%$ of caregivers). Percentages may add up to over $100 \%$ as some families were multi-racial. Caregivers' highest level of education included: high school graduate or less $(9 \%)$, some college or technical school $(47 \%)$, college graduate $(19 \%)$ or graduate degree (25\%). Children that participated in the study had an average age of 4.66 years $(S D=1.36), 66 \%$ were male, and families had an average household monthly income of $\$ 6,596(S D=\$ 6,224)$. Participating children had an average pre-treatment ECBI Score of $172.83(S D=26.29)$. For the current study 3 families were excluded because they did not have a codable CDI Coach 2 session, resulting in a final sample of $n=29$ from PersIn. Together with the $n=20$ from the GANA sample, there was a combined total of $n=49$ subjects for the analyses.

Therapists: Therapists in the GANA study $(\mathrm{n}=4)$ were bilingual practicum students from M.S.W. and professional psychology doctoral programs, while therapists in the PersIn study $(n=9)$ were staff therapists and student interns at as well as a faculty therapist Therapists in both studies were either previously trained in PCIT and were provided with calibration and training 
specific to the cultural adaptation, or were provided with 40 hours of training in PCIT in addition to training in cultural modifications by the principal investigator. The PI then provided consultation on all cases in the PCIT conditions. All therapists had $1 \mathrm{hr}$ of face-to-face individual supervision per week.

\section{Measures}

Eyberg Child Behavior Inventory (ECBI; Eyberg et. al. 1999) is a 36-item parent report measure of young children's disruptive behavior with evidence supporting its reliability and validity for both English and Spanish versions (Garcia-Tornel et al, 1998). Internal consistency for the Intensity Scale, which reflects frequency of disruptive behaviors, was $\alpha=.86$ for the GANA sample and $\alpha=.88$ for the PersIn sample. The ECBI Intensity Scale was used to determine eligibility for the study, and was then used to track the change in the child's problem behaviors over the course of treatment. The clinical cutoff for eligibility in the study was a score of 131 or higher.

Therapist-Parent Interaction Coding System (TPICS; Barnett et. al. 2014 \& Barnett et al., 2017). The TPICS is an observational coding system that can be used to code a range of therapist behaviors that take place during the skill coaching portion of PCIT (see Table 1). The TPICS provides guidelines for coding a number of theoretically important therapist variables: modeling (MO), prompting (PR), reflective descriptions (RD), direct and indirect commands (DC, IC), praises (LP, UP), process comments (PC), assurance comments (AC), and rationale remarks (RR; Barnett et. al. 2017). These codes can be divided into directive or responsive categories. Directive verbalizations are only those that occur prior to a parent verbalization that tell the parent what to do (i.e. MO, PR, DC and IC). Responsive statements occur following a parent 
verbalization in order to provide feedback and reinforcement to parent skill usage (i.e. LP, UP,

RD, PC). We also used the TPICS code for "Mistake" (M) to determine therapist accuracy. If a therapist mislabeled or incorrectly reinforced a parent's use of skills, the therapist's response would be coded as a mistake.

\section{Table 1}

Therapist-Parent Interaction Coding System Therapist Categories

\begin{tabular}{|c|c|c|}
\hline Coaching Technique & Definition & Example \\
\hline \multicolumn{3}{|l|}{ Directive Techniques } \\
\hline Modeling (MO) & $\begin{array}{l}\text { Therapist verbalization or a } \\
\text { parent-child interaction } \\
\text { therapy parenting skill. }\end{array}$ & $\begin{array}{l}\text { "Thank you for sharing with } \\
\text { me." }\end{array}$ \\
\hline Prompting (PR) & $\begin{array}{l}\text { Therapist verbalization of the } \\
\text { beginning of an appropriate } \\
\text { skill intended to allow a } \\
\text { parent to finish the statement. }\end{array}$ & "Thank you for..." \\
\hline Direct Command (DC) & $\begin{array}{l}\text { Therapist declarative } \\
\text { statement that contains a } \\
\text { direction for a behavior to be } \\
\text { performed by the parent. }\end{array}$ & "Praise him for sharing." \\
\hline Indirect Command (IC) & $\begin{array}{l}\text { Therapist suggestion for a } \\
\text { behavior to be performed by } \\
\text { the parent. }\end{array}$ & $\begin{array}{l}\text { "Can you think of something } \\
\text { to praise him for?" }\end{array}$ \\
\hline Drill (DR) & $\begin{array}{l}\text { An exercise during which the } \\
\text { therapist tells the parent to } \\
\text { focus on one targeted } \\
\text { parenting behavior for a } \\
\text { specified duration or } \\
\text { frequency. }\end{array}$ & $\begin{array}{l}\text { "We are going to see how } \\
\text { many labeled praises you can } \\
\text { give him in one minute." }\end{array}$ \\
\hline Child Observation (CO) & $\begin{array}{l}\text { Any therapist observation } \\
\text { about the child that is used to } \\
\text { draw the parent's attention to }\end{array}$ & "He just shared with you." \\
\hline
\end{tabular}


the child.

\section{Responsive Techniques}

Labeled Praise (LP)

Process Comment (PC)

Reflective Description (RD)

Unlabeled Praise (UP)

Corrective Criticism (CC)

Rationale Remark (RR)

Assurance Comment (AC)
No Response (NR)

Therapist verbalization that provides a positive evaluation of a specific behavior, activity, product, or verbalization of the parent.

Therapist statement that ties a child's behavior to the parent's treatment-related behavior.

Therapist non-evaluative, declarative sentence or phrase about the parent's most recent verbalization or behavior.

Therapist verbalization that provides nonspecific positive evaluation of the parent or parent's behavior.

Exclusion Explanation (EE)

Therapist verbalization that is negatively stated or gently critical of a parent's behaviors.

Statements that educate the parent about skills and behaviors to avoid.

Statements that educate the parent about treatmentrelated skills and procedures.

Statements that describe or reframe a parent or child behavior as expected, typical/normal, challenging or tolerable.

Instances where a parent's use of a do skill (LP, RF, BD) is
"That was a great labeled praise you gave him."

"She shared again because you praised her for that."

"That was an unlabeled praise."

"Excellent job!"

"Stop paying attention to that behavior."

“Don't imitate his misbehavior or you will see it increase."

"Behavior descriptions help to keep his focus at the table."

"I know it's hard to stay calm when he's yelling."

Parent: "You're playing so gently with the toys!" 
not immediately praised/reinforced or use of a don't skill (NTA, IC, DC, QU) is not immediately commented on.

Mistake (M)
Instances where the therapist responds incorrectly to the parent's use of a skill.
Therapist: "Now describe what he's doing." (didn't praise parent's use of LP)

Note: From Barnett, Niec, and Peer (2013) with edits.

Additional Therapist Codes: For the current study, we developed a new set of guidelines for coding therapist behaviors that was compatible with the DPICS/TPICS. First, we used the transcriptions to measure therapist brevity by counting the number of words in each coaching statement. Second, we measured therapist positivity by calculating the percent of coaching statements that were coded as praise (LP or UP). Third, to measure consistency we developed a code for missed opportunities, also called No Responses (NR), which are instances where a parent's use of a do skill (LP, RF, BD) is not immediately praised/reinforced. A response was only considered immediate if it was preceded by only one verbalization (only a TA or UP) following the parent's use of a skill.

Speed of Parental Skill Acquisition. Parental skill acquisition was defined as the number of sessions to completion of CDI for families that graduated from CDI. Five families were excluded from these analyses due to the fact that they dropped out prior to meeting CDI mastery.

Treatment Completion. Treatment completion was defined as meeting criteria for graduation from PCIT which includes mastery of CDI, mastery of PDI, ECBI $\leq 114$, and the 
parent feeling comfortable handling their child's problems. Of the $n=49$ families, $35.7 \%$ ( 17 families) dropped from treatment.

\section{Procedure}

For both the GANA and PersIn studies, families were referred to the study by community clinics, headstarts, and outreach to the community. Families were screened for eligibility by a bilingual RA on the phone. Eligible families then completed a 3-4 hour pre-treatment assessment in person, in which they gave informed consent and completed additional parent report questionnaires about family demographics, parent and child mental health symptoms, and parent perceptions of treatment, as well as completing the DPICS observation (McCabe et. al 2020). Families were paid $\$ 100$ for each assessment. In the GANA study, families were then randomly assigned to receive a culturally modified version of PCIT called GANA, Guiando a Niños Activos (GANA), standard PCIT, or treatment as usual (TAU). GANA retained the core features of PCIT, and added culturally relevant elements designed to better engage families of Mexican American ethnicity. In the PersIn study, all families received a personalized version of PCIT that was developed as a method of reducing incongruence in the parent explanatory models (PEMs) of families. When families either graduated from treatment or dropped out, they were re-contacted to complete a second post-treatment interview. Many of the parent-report questionnaires that were completed pre-treatment were readministered in the post-treatment assessment (Barnett et. al. 2017, McCabe et. al 2020), and the DPICS was repeated.

Coding TPICS: To standardize our sample, we chose to TPICS code transcriptions of video recordings of the first five minutes of the third session of PCIT, which is the second coaching session of the Child Directed Interaction (CDI-C2) phase of PCIT. We chose the second 
coaching session because the therapist and family would have established rapport but would still be early enough in treatment that therapist behaviors would be likely to influence engagement.

The coders $(\mathrm{n}=4)$ were graduate and undergraduate research assistants. Prior to beginning to code, coders were required to reach mastery ( $\geq 80 \%$ agreement) of the DPICS with a criterion tape. Next, coders had to complete 4 practice TPICS transcripts, and received feedback on their performance, before being tested. As a final step, coders were required to reach $\geq 80 \%$ agreement on a master transcript coded by the author of the TPICS systems, Dr. Barnett.

Each coder coded a total of 16 transcripts each, and were blinded to condition. A 25\% sample $(\mathrm{n}=18)$ was randomly chosen to be double-coded for inter-rater reliability. Interrater reliability across all TPICS codes was 79\%. Coders and supervisors met bi-weekly during the coding period to discuss any coding differences. However, discussion of codes were not used to modify any previously coded transcripts.

\section{Results}

First we examined the frequencies of the coaching behaviors as well as their intercorrelations with one another (see Tables 2 and 3). Therapists were, on average, $41.96 \%$ $(\mathrm{SD}=18.20)$ positive, $61.68 \%(\mathrm{SD}=25.16)$ consistent, and $91.32 \%(\mathrm{SD}=9.16)$ accurate, with an average of $20.43(\mathrm{SD}=12.46)$ directive verbalizations, $23.55(\mathrm{SD}=10.52)$ responsive verbalizations and $5.12(\mathrm{SD}=1.15)$ words per statement in a five minute period. Therapists averaged a total of 20.12 praises $(\mathrm{SD}=8.98)$ with a mean $68.4 \%(\mathrm{SD}=.26)$ of those being labeled praises. ECBI Intensity Sums were an average of $175.67(\mathrm{SD}=27.67)$ pre-treatment and 91.98 $(\mathrm{SD}=33.43)$ post-treatment, and the mean number of $\mathrm{CDI}$ sessions as $7.88(\mathrm{SD}=2.93)$. The 
correlation between directive therapist verbalizations and therapist positivity exceeded threshold for multicollinearity $(r=-.759, p<.001)$, and therefore could not be included in the same regression models. For the speed of acquisition analyses only, 5 cases were excluded as the families dropped from treatment before beginning PDI, and therefore did not complete CDI.

\section{Table 2}

Correlations Between Predictors

\begin{tabular}{llllllll}
\hline & 1 & 2 & 3 & 4 & 5 & 6 & 7 \\
\hline 1.ECBI Intensity Sum (Pre) & 1 & & & & & & \\
2.Brevity & .036 & 1 & & & & & \\
3.Positivity & .115 & $-.353^{*}$ & 1 & & & & \\
4.Accuracy & .135 & .026 & -.204 & 1 & & & \\
5.Consistency & 079 & -.110 & $.581 * *$ & .004 & 1 & & \\
6.Directiveness & -.090 & -.018 & $-.759 * *$ & .080 & $-.429 * *$ & 1 & \\
7.Responsiveness & .233 & -.260 & $.472 * *$ & -.236 & $-.446^{* *}$ & -.155 & 1 \\
\hline
\end{tabular}

$*$ Correlation is significant at the 0.05 level (2-tailed)

**Correlation is significant at the 0.01 level (2-tailed)

Note. Threshold for multicollinearity is 0.7 .

\section{Table 3}

Descriptive Statistics for Study Variables and Coaching Recommendations

\begin{tabular}{lll}
\hline Variable & Mean & $\begin{array}{l}\text { Standard } \\
\text { Deviation }\end{array}$ \\
\hline Number of CDI Sessions & 7.88 & 2.93 \\
ECBI Intensity Sum at Pre & 175.67 & 27.67
\end{tabular}




\begin{tabular}{lll} 
ECBI Intensity Sum at Post & 91.98 & 33.43 \\
Words Per Coaching Statement & 5.12 & 1.15 \\
Therapist Positivity & $41.96 \%$ & 18.20 \\
& & \\
Therapist Accuracy & $91.32 \%$ & 9.16 \\
$\begin{array}{l}\text { Therapist Consistency } \\
\text { Total Directive Therapist }\end{array}$ & $61.68 \%$ & 25.16 \\
$\begin{array}{l}\text { Verbalizations } \\
\text { Total Responsive Therapist }\end{array}$ & 20.43 & 12.46 \\
Verbalizations & 23.55 & 10.52 \\
\hline
\end{tabular}

This descriptive data was examined to determine what percentage of therapists are following the recommendations as set by McNeil et al. (2010; see Table 3). $57.1 \%$ of therapists met the recommendation for brevity: an average of 5 or fewer words per statement. Therapists met the recommendation for positivity for $87.7 \%$ of cases, with at least 10 statements of praise in the 5 minute coaching session, and at least $50 \%$ being labeled. For consistency, $28.6 \%$ of therapists met the recommendation of 3 or fewer instances of NR. For accuracy, $79.6 \%$ of therapists met the recommendation of 3 or fewer mistakes. For responsive and directive coaching, $67.3 \%$ of therapists met the recommendation that the number of responsive verbalizations must be greater than the number of directive verbalizations. Overall, $8.2 \%$ of therapists met all 5 recommendations.

Next, we examined the ability of therapist behaviors to predict each of the outcome variables: rate of parental skill acquisition, child outcome, and treatment completion. Predictors included: (1) therapist accuracy (percent of verbalizations in which the therapist correctly 
identified parent skills), (2) therapist consistency (the percent of time that the therapist responds to parent "do" skills), (3) brevity (words per coaching statement), (4) therapist praise/positivity, (5) total responsive therapist verbalizations, and (6) total directive therapist verbalizations. Because of the strong negative relationship between therapist directiveness and positivity, we separated our predictors into two models for each outcome variable. Models labeled "a" included predictors 1-4, and models labeled "b" included predictors 5 and 6. Model "a" includes the recommended therapist behaviors and model " $b$ " examines only the predictive value of responsive and directive coaching. In addition, each model was computed twice, once with covariates and once without. The three covariates used in the models were: Condition (PersIn, GANA or standard PCIT), ECBI Intensity score at pre-treatment, and PSI Intensity score pre-treatment. Language was not included as a covariate in this study because it broke the threshold for multicollinearity with Condition.

Model $1 \mathrm{a}$ and $\mathrm{b}$ are linear regressions examining the predictors of the rate of parent skill acquisitions as measured by number of CDI sessions, excluding the five cases that did not begin PDI. The overall Model 1a was not significant $\left(F(7,41)=1.340, p=.257 ; R^{2}=.186\right)$. The overall Model 1b was also not significant, $\left(F(5,43)=1.507, p=.208 ; R^{2}=.149\right)$, and none of the therapist behaviors significantly predicted speed of skill acquisition.

Model $2 \mathrm{a}$ and $\mathrm{b}$ are linear regression models examining the predictors of improvement in child behavior problems from pre to post treatment as assessed by ECBI intensity scores. Model 2a was not significant $\left(F=(7,39)=1.368, p=.246 ; R^{2}=.197\right)$. Model $2 \mathrm{~b}$ also was not significant $\left(F(5,41)=1.166, p=.342 ; R^{2}=.125\right)$. 
Model $3 \mathrm{a}$ and $\mathrm{b}$ (See Table 4) are logistic regression models examining the prediction of treatment completion versus treatment drop out. Model 3a was significant $\left(\chi^{2}(8)=31.500\right.$, Nagelkerke $R^{2}=.654, p<.001 ; 89.8 \%$ accurate classification), with therapist positivity as the only significant predictor of treatment completion $(\mathrm{B}=.135$, Wald $=5.632, p=.018 ; O R=$ 1.144). For every percentage point increase in therapist positivity, there is a $14.4 \%$ increased chance of completing treatment. This model explained $65 \%$ of the variance in treatment completion. Independent samples t-tests (which did not include covariates) showed that treatment completers had significantly higher average rates of therapist praise (47\%) compared to treatment non-completers $(32 \% ; t(47)=3.089, p=.003)$.

The overall model $3 \mathrm{~b}$ was significant, $\left(\chi^{2}(6)=25.987\right.$, Nagelkerke $R^{2}=.568, p<.001$; 81.6\% accurate classification). Responsive and Directive therapist verbalizations significantly predicted completion (See Table 4), with responsive positively predicting completion $(\mathrm{B}=.128$, Wald $=4.449, p=.035, O R=1.137)$, and directive negatively predicting completion $(\mathrm{B}=-.126$, Wald $=4.728, p=.030, O R=.882$ ). For every additional responsive verbalization, there was a $13.7 \%$ increased chance of completing treatment, and for every additional directive verbalization, there was a $11.8 \%$ decreased chance of completing treatment. Independent samples t-tests, which did not include covariates, showed that the difference in rates of directive verbalizations between treatment completers $(M=18.75)$ and non-completers $(M=23.59)$ was not statistically significant $(t(47)=1.304, p=.199)$. However, treatment completers had significantly higher rates of responsive verbalization $(M=26.75)$ compared to treatment non-completers $(M=17.53 ; t(47)=3.188, p=.003)$. 
Table 4

Relation of Therapist Behaviors Treatment Completion

\begin{tabular}{llllllll}
\hline Model & Model Predictor & B & S.E. & Wald & df & $p$ & Exp $(B)$ \\
\hline $3 \mathrm{a}$ & Therapist Positivity & .135 & .057 & 5.632 & 1 & .018 & 1.144 \\
& Brevity & .167 & .466 & .129 & 1 & .720 & 1.182 \\
& Therapist Consistency & .016 & .025 & .414 & 1 & .520 & 1.016 \\
& Therapist Accuracy & .012 & .056 & .044 & 1 & .834 & 1.012 \\
$3 \mathrm{~b}$ & $\begin{array}{l}\text { Directive Therapist } \\
\text { Verbalizations }\end{array}$ & -.126 & .058 & 4.728 & 1 & .030 & .882 \\
& $\begin{array}{l}\text { Responsive Therapist } \\
\text { Verbalizations }\end{array}$ & .128 & .061 & 4.449 & 1 & .035 & 1.137 \\
& & & & & & \\
\hline
\end{tabular}

\section{Discussion}

The current study sought to determine the frequency with which therapists use a range of coaching behaviors, including brevity, positivity, consistency, accuracy, directiveness and responsiveness, that have been hypothesized to be important in producing positive outcomes in an ethnically diverse sample of families in PCIT. On average this group of relatively inexperienced PCIT therapists met or exceeded the recommended guidelines for therapist accuracy, brevity, positivity, responsiveness, and directiveness. However, therapists were much below recommended levels for consistency, suggesting that this skill may be harder for emerging therapists to master and may require further attention in training. Furthermore, we examined the relationship between these therapist coaching behaviors and parent's speed of skill acquisition, child symptom improvement, and treatment retention. Contrary to hypotheses, findings revealed 
that none of the therapist behaviors examined predicted the outcomes of speed of parental skill acquisition or child outcome. However, therapist positivity and responsive coaching were significantly positively related to treatment completion, while therapist directiveness was significantly negatively related to treatment completion. Although two of our hypotheses were not supported, our findings are generally consistent with the past literature regarding the importance of responsive coaching. Furthermore, our findings also highlight the importance of positivity, and provide new evidence of a significant relationship between directive coaching and treatment dropout. In addition, this study extends these findings to a culturally diverse sample that includes both Spanish and English speaking therapists.

Our findings replicate a number of previous studies that have found responsiveness to be an important predictor of engagement in PCIT. In the current study, responsiveness was a significant predictor of treatment completion, consistent with the findings of Barnett et al., (2017). Harwood and Eyberg (2004) have suggested that "the early therapist-parent relationship in PCIT may be critical to successful treatment completion," and that responsiveness plays an important role in establishing this relationship. Responsive coaching, which includes techniques such as praising parent skill use, labeling parents use of skills, and describing the effects of parent's skills on the child, are powerful teaching tools to elicit behavior change (Barnett et al., 2013). Taken together with past literature, our findings suggest that responsiveness is a consistent predictor of treatment completion in PCIT and should be emphasized in therapist training as a core skill. Furthermore, responsiveness appears to have a similar importance in ethnic minority and Non-Hispanic White samples. 
The current study also found that therapist directiveness was significantly negatively related to treatment completion. This is somewhat different that was has been found in other studies, which suggested that directiveness was either unrelated to outcomes, such as speed of skill acquisition and treatment or completion, or that some components (ie. drills) were negatively related to treatment completion, while overall directiveness was not (Barnett et al., 2017). Although this may lead to the conclusion that coaches should refrain from using directive over responsive coaching statements as much as possible, it must be taken in the context of previous research by Barnett et al. (2017) which noted that although directive coaching is not as effective as responsive coaching, a combination of the two can be beneficial as parents learn new skills. For example, when parents are "stuck" and unable to generate a skill on their own it may be effective to get them started by suggesting a skill (e.g., "Why don't you tell him that you love the way he is sitting so quietly.”). Thus, future research should examine whether specific components of directive coaching, such as drills or corrective criticism are detrimental, while other components such as modeling may still be beneficial when combined with responsive coaching (Barnett et al., 2017).

Consistent with therapist guidelines proposed by McNeil \& Hembree-Kigin (2010), therapist positivity was significantly related to treatment completion. In a number of studies, positivity has been highlighted as an important skill because positive reinforcement emphasizes the parent's correct use of skills and is more effective than criticism in eliciting desired behaviors from the parent (McNeil et al., 2010). In PCIT, therapists train parents to praise child positive behaviors and ignore their misbehaviors; this positive reinforcement is the centerpiece of the methods PCIT uses to increase children's prosocial behaviors. Similarly, when therapists use 
positive reinforcement in response to parent skill use, they are modeling both the way in which praise works to change their child's behavior, while also motivating parents to increase their own skill use. However, as in previous other studies, responsive coaching was not a significant predictor of child symptom improvement, possibly because it is such a distal outcome relative to the five minute sample of coaching taken early in treatment. Furthermore, we did not find a relationship between responsiveness and speed of skill acquisition, which differs from the findings of Heymann et al. (2021), in which responsive coaching statements in both English and Spanish had a positive impact on parental skill acquisition, and from Barnett et al. (2017) in which higher rates of responsive coaching predicted faster parental skill acquisition. This may be because of the fact that we operationalized speed of skill acquisition as the number of sessions to CDI mastery, whereas past studies have only examined skill acquisition from one session to the next (Barnett et al., 2017).

The current study did not find support for the effect of a number of other therapist behaviors theorized to predict outcomes in PCIT. For example, McNeil \& Hembree-Kigin (2010) have suggested that therapist coaching statements should be kept brief in order to reduce cognitive load; however, in the current study, brevity was unrelated to outcomes. There are a number of possible reasons for this. First, it has been suggested that Spanish speaking therapists may have higher wordiness than English speaking therapists because a statement in English typically translates to more words in Spanish (Why Spanish, 2021). Therefore, longer statements may be more appropriate in cases conducted in Spanish, and because our sample included a large proportion of Spanish speakers, it may have influenced the results. Second, although it is generally recommended to keep coaching statements brief, there may be good reasons to make a 
longer statement in some cases, depending on the skill being addressed. For example, a response to a Labeled Praise could be either, "great labeled praise" (3 words), or a Process Comment, "she is sharing more because you praised her for that" (10 words). There may be times in coaching when process comments can be particularly powerful. Thus, use of an average number of words per statement as a representation of brevity may not reflect the strategic choices that therapists may be making.

Somewhat surprisingly, accuracy, or the percentage of time that coaches correctly identified a parent skill, was also not a significant predictor of any of our outcomes variables. Although it seems reasonable to suppose that accurate coaching of parents' skill is an essential component of treatment, as has been argued in past literature (Barnett et al., 2018), an empirical link to treatment outcomes has not been documented. It is theoretically possible that positive reinforcement of any kind is more important than an accurate label of the skills (e.g., saying "Great labeled praise" after a parent uses a behavioral description would still reinforce the skill). However, it is also possible that this relationship may not have been observed in the current sample because the therapists in this study were relatively accurate $(91 \%)$, thus restricting the range of this variable. Future studies that include a wider range of accuracy would be necessary to make a firm determination of the nature of this relationship.

Our current findings also failed to support the relationship between therapist consistency, or the percentage of time that the therapist responds to the parent's use of "do" skills, and outcomes. Although this variable has not been empirically examined in past studies, it has been suggested to be a critical element of coaching (McNeil et al., 2010). However, our findings suggest that therapists can still be quite effective when their consistency is below recommended 
levels. This may be because of the fast pace of the interaction, or because intermittent reinforcement can still produce behavior change. Future research should focus on determining what level of consistency is needed or optimal for producing parent skill acquisition and engagement.

This study has some particular strengths that have not been included in past studies. The ethnically diverse and large sample used in this study was an important strength in assessing the effect of therapist coaching behaviors among groups underrepresented in research. Additionally, past studies examining coaching behaviors in PCIT have had low dropout rates because therapists have been at the expert level (Barnett et al., 2017), making it harder to accurately predict treatment completion. Because of the use of novice therapists as well as a diverse client population in this study, we see a much higher dropout rate, which allows us to examine the particular behaviors that predict treatment completion. The inclusion of coaching behaviors that had not yet been examined prior to this study is another strength, allowing us to begin to identify which of the previously theorized to be important are actually supported by empirical evidence. However, the results of this study are limited by the combination of two samples that were collected at different points in time as well as a high rate of missing session tapes, particularly from the GANA sample. In addition, some of our therapist coaching behaviors, such as accuracy, may not have a wide enough range to detect an association with outcomes.

Future research comparing novice therapists to more experienced therapists could not only provide insight into the frequency of therapist behaviors associated with client success, and identify important targets for therapist training, but also give us more information about how coaching changes as therapists become more experienced. It would also be useful to also 
examine parent behaviors, such as how responsive the parent is to therapist directives, as the parent's responsiveness determines the amount of therapist coaching opportunities. For example, parental resistance might lead therapists to become more directive, which may lead to more resistance from the parent and possibly eventual dropout (Patterson \& Forgatch, 1985). Barnett et al. (2013) has also found that therapists used more directive coaching when parents demonstrated deficits in the "do" skills, particularly Labeled Praises and Behavior Descriptions, suggesting that parent skill levels and therapist coaching behaviors may have a bi-directional relationship. Controlling for parent-generated "do" skills may help us tease apart this relationship. It could also be interesting to analyze parent skill acquisition using the change between parent skills in the pre-treatment DPICS to post treatment. With this, it would also be important to examine if dropout for families occurred because they were not getting enough "do" skills or if they met the criteria for "do" skills but were not below the limit for "don't" skills. In conclusion, the findings of this study contribute to our understanding of important therapist behaviors which can help clarify targets for therapist training that will optimize family success. 


\section{References}

Abidin, R. R. (1997). Parenting Stress Index: A measure of the parent-child system. In C. P. Zalaquett \& R. J. Wood (Eds.), Evaluating stress: A book of resources. (pp. 277-291). Retrieved from http://search.ebscohost.com/login.aspx?direct=true\&db=psyh\&AN=1997-09146-015\&sit $\mathrm{e}=$ ehost-live

Achenbach, T.M. (1991). Manual for the Child Behavior Checklist/4-18 and 1991 Profile. Burlington, Vt: University of Vermont, Department of Psychiatry

Barnett, M.L., Niec, L.N., Acevedo-Polakovich, D. (2013). Assessing the Key to Effective Coaching in Parent-Child Interaction Therapy: The Therapist-Parent Interaction Coding System. Journal of Psychological Behavioral Assessment. DOI 10.1007/s10862-013-9396-8.

Barnett, M.L., Niec, L.N., Peer, S.O. (2014). Manual for the Therapist Parent Interaction Coding System (TPICS) - Child Directed Interaction Component. CMU Center for Children, Families, and Communities.

Barnett, M. L., Niec, L. N., Peer, S. O., Jent, J. F., Weinstein, A., Gisbert, P., \& Simpson, G. (2017). Successful therapist-parent coaching: How in vivo feedback relates to parent engagement in parent-child interaction therapy. Journal of Clinical Child and Adolescent 
Psychology, 46(6), 895-902.

https://doi-org.sandiego.idm.oclc.org/10.1080/15374416.2015.1063428

Barnett M.L., Davis E.M., Schoonover C.E., Niec L.N. (2018) Therapist-Parent Interactions in PCIT: The Importance of Coach Coding. In: Niec L. (eds) Handbook of Parent-Child Interaction Therapy. Springer, Cham. https://doi.org/10.1007/978-3-319-97698-3_19

Bjørseth, A., Wichstrøm, L. (2016). Effectiveness of Parent-Child Interaction Therapy (PCIT) in the Treatment of Young Children's Behavior Problems: A Randomized Controlled Study. PLoS One. DOI: 10.1371/journal.pone.0159845

Bloom B, Jones LI, Freeman G. Summary health statistics for U.S. children: National Health Interview Survey, 2012. National Center for Health Statistics. Vital Health Stat 10(258). 2013.

Boggs, S. R., Eyberg, S. M., Edwards, D. L., Rayfield, A., Jacobs, J., Bagner, D., \& Hood, K. K. (2005). Outcomes of parent-child interaction therapy: A comparison of treatment completers and study dropouts one to three years later. Child \& Family Behavior Therapy, 26, 1-22. doi:10.1300/j019v26n04_01

Boylan K, Vaillancourt T, Boyle M, Szatmari P. Comorbidity of internalizing disorders in children with oppositional defiant disorder. European Child Adolescent Psychiatry. 2007;16(8):484-494. doi:10.1007/s00787-007-0624-1 
Burke JD, Hipwell AE, Loeber R. Dimensions of oppositional defiant disorder as predictors of depression and conduct disorder in preadolescent girls. Journal American Academy Child Adolescent Psychiatry. 2010;49(5):484-492.

Chacko A, Wymbs BT, Wymbs FA, et al. Enhancing traditional behavioral parent training for single mothers of children with ADHD. Journal of Clinical Child Adolescent Psychol. 2009;38(2):206-218. doi:10.1080/15374410802698388

Chaffin et al. (2013). Parent-Child Interaction Therapy With At-Risk Families. Child Welfare Information Gateway. http://www.pcit.org/uploads/6/3/6/1/63612365/pcit-with-at-risk_families.pdf

Chaffin M, Valle LA, Funderburk B, et al. (2009). A motivational intervention can improve retention in PCIT for low-motivation child welfare clients. Child Maltreatment. 14(4):356-368. doi: 10.1177/1077559509332263

Danko, C. M., Garbacz, L. L., \& Budd, K. S. (2016). Outcomes of Parent-Child Interaction Therapy in an urban community clinic: A comparison of treatment completers and dropouts. Children and Youth Services Review, 60, 42-51. doi: 10.1016/j.childyouth.2015.11.007

Dawson, A., Fain, K., McCabe, K.M., \& Yeh, M., (April, 2015). Predictors of treatment outcome for Mexican American families in Parent Child Interaction Therapy. Poster presented at the annual meeting of the Western Psychological Association, Las Vegas, NV. 
Eyberg SM, Funderburk B. Parent Child Interaction Therapy Protocol. Gainesville, FL: PCIT International; 2011

Eyberg, S.M., \& Pincus, D. (1999). Eyberg Child Behavior Inventory and Sutter-Eyberg Student Behavior Inventory-Revised: Professional Manual. Odessa, FL: Psychological Assessment Resources.

Eyberg, S. M., Nelson, M. M., \& Boggs, S. R. (2008). Evidence-based psychosocial treatments for children and adolescents with disruptive behavior. Journal of Clinical Child and Adolescent Psychology, 37, 215-237. doi:10.1080/15374410701820117

Eyberg, S.M., Chase, R.M., Fernandez, M.A., Nelson, M.M. (2014). Dyadic Parent-Child Interaction Coding System (DPICS) Clinical Manual, 4th ed. PCIT International, Inc.

Fernandez, M. A., \& Eyberg, S. M. (2009). Predicting treatment and follow-up attrition in parent-child interaction therapy. Journal of Abnormal Child Psychology, 37, 431-441. doi:10.1007/s10802-008- 9281-1

Funderburk, B. W., \& Eyberg, S. (2011). Parent-child interaction therapy. In J. C. Norcross, G. R. VandenBos, \& D. K. Freedheim (Eds.), History of psychotherapy: Continuity and change., 2nd ed. (pp. 415-420). Washington, DC: American Psychological Association. https://doi-org.sandiego.idm.oclc.org/10.1037/12353-021

Garcia-Tornel, S., Calzada, E. J., Eyberg, S. M., Alguacil, J. M., Serra, C. V., Mendoza, C. B., et 
al. (1998). Inventario Eyberg del Comportamiento en Niños: Normalización de la versión española y su utilidad para el pediatra extrahospitalario. Anales Españoles de Pediatria, $48,475-482$.

Gulanick, N., \& Schmeck, R. R. (1977). Modeling, praise, and criticism in teaching empathic responding. Counselor Education and Supervision, 16 , 284-290. doi:10.1002/j.1556-6978.1977.tb01027.x.

Heymann, P., Heflin, B. H., \& Bagner, D. M. (2021). Effect of Therapist Coaching Statements on Parenting Skills in a Brief Parenting Intervention for Infants. Behavior Modification. https://doi.org/10.1177/0145445520988140

Harwood, Michelle D. \& Eyberg, Sheila M. (2004) Therapist Verbal Behavior Early in Treatment: Relation to Successful Completion of Parent-Child Interaction Therapy, Journal of Clinical Child and Adolescent Psychology, 33:3, 601-612, DOI: $10.1207 / \mathrm{s} 15374424 \mathrm{jccp} 3303 \_17$

Holden, G. W., Lavigne, V. V., \& Cameron, A. M. (1990). Probing the continuum of effectiveness in parent training: Characteristics of parents and preschoolers. Journal of Clinical Child Psychology, 19, 2-8. doi:10.1207/s15374424jccp1901_1

Kaminski, J. W., Valle, L.A., Filene, J.H. et al. A Meta-analytic Review of Components Associated with Parent Training Program Effectiveness. Journal of Abnormal Child Psychology, 36, 567-589 (2008). https://doi.org/10.1007/s10802-007-9201-9

Keil, V., \& Price, J. M. (2006). Externalizing behavior disorders in child welfare settings: Definition, prevalence, and implications for assessment and treatment. Children and 
Youth Services Review, 28(7), 761-779.

https://doi-org.sandiego.idm.oclc.org/10.1016/j.childyouth.2005.08.006

Lieneman, C.C., Quetsch, L.B., Theodorou, L.L., Newton, K.A., McNeil, C.B. (2019).

Reconceptualizing attrition in Parent-Child Interaction Therapy: "dropouts" demonstrate impressive improvements. Psychology Research and Behavior Management, Vol. 12 (pp. 543-555). DOI: https://doi.org/10.2147/PRBM.S207370

Loeber R, Burke, JD, Lahey BB, Winters A, Zera M. Oppositional defiant and conduct disorder: A review of the past 10 years, Part I. Journal American Academy Child Adolescent Psychiatry. 2000;39(12):1468-1484. doi: 10.1097/00004583-200012000-00007

McCabe, K. M., Yeh, M., \& Zerr, A. A. (2020). Personalizing Behavioral Parent Training Interventions to Improve Treatment Engagement and Outcomes for Culturally Diverse Families. Psychology Research and Behavior Management, Volume 13, 41-53. doi: $10.2147 /$ prbm.s230005

McCabe, K.M., Sakamoto, M., Green Rosas, Y., Kehoe, K., La, R., Zerr, A., Yeh, M. (2020). Keeping an "I" on PRIDE: Measuring Imitation in Parent Child Interaction Therapy.

McCabe, K.M., Yeh, M. (2009). Parent-Child Interaction Therapy for Mexican Americans: A Randomized Clinical Trial. Journal of Clinical Child \& Adolescent Psychology, 38:5, 753-759, DOI: $10.1080 / 15374410903103544$ 
McNeil, Cheryl, Hembree-Kigin, Toni L. Parent Child Interaction Therapy. Issues in Clinical Child Psychology. 2010. 2nd ed. (77-101). Springer US. DOI:

$10.1007 / 978-0-387-88639-8$

Nock MK, Kazdin AE. Randomized controlled trial of a brief intervention for increasing participation in parent management training. Journal Consult Clinical Psychology. 2005;73(5):872-879. doi:10.1037/0022-006X.73.5.872

Nowak, C., Heinrichs, N. A Comprehensive Meta-Analysis of Triple P-Positive Parenting Program Using Hierarchical Linear Modeling: Effectiveness and Moderating Variables. Clinical Child Family Psychology Review, 11, 114 (2008).

https://doi.org/10.1007/s10567-008-0033-0

Patterson, G. R., \& Forgatch, M. S. (1985). Therapist behavior as a determinant for client noncompliance: A paradox for the behavior modifier. Journal of Consulting and Clinical Psychology, 53, 846-851. doi:10.1037//0022-006x.53.6.846

Pearl, E., Thieken, L., Olafson, E., Boat, B., Connelly, L., Barnes, J., \& Putnam, F. (2012). Effectiveness of community dissemination of parent- child interaction therapy. Psychological Trauma: Theory, Research, Practice, and Policy, 4, 204-213. doi:10.1037/a0022948 
Scott S, Knapp M, Henderson J, Maughan B. Financial cost of social exclusion: follow up study of antisocial children into adulthood. BMJ. 2001;323:191-194. doi:

10.1136/bmj.323.7306.191

Storch, J.F. (2016). Inclusion, Effective Practices, and Coaching in Early Childhood Education. ProQuest, University of Florida.

Strayhorn, J. M., \& Weidman, C. S. (1988). A parent practices scale, and its relation to parent and child mental health. Journal of the American Academy of Child and Adolescent Psychiatry, 27, 613-618.

Traux, C. B. (1968). Therapist interpersonal reinforcement of client self-exploration and therapeutic outcome in group psychotherapy. Journal of Counseling Psychology, 15(3), 225-231. doi:10.1037/h0025865.

Tremblay, R. E., Masse, B., Perron, D., Leblanc, M., Schwartzman, A. E., \& Ledingham, J. E. (1992). Early disruptive behavior, poor school achievement, delinquent behavior, and delinquent personality: Longitudinal analyses. Journal Consult Clinical Psychology, 60(1), 64-72. doi: 10.1037/0022-006X.60.1.64

Vogel M, Messner SF. Social correlates of delinquency for youth in need of mental health services: examining the scope conditions of criminological theories. Justice $Q$. 2012;29(4):546-572. doi:10.1080/07418825.2011.582879 
Ward, M. A., Theule, J., \& Cheung, K. (2016). Parent-child interaction therapy for child disruptive behaviour disorders: A meta-analysis. Child \& Youth Care Forum, 45(5), 675-690. https://doi-org.sandiego.idm.oclc.org/10.1007/s10566-016-9350-5

Werba, B. E., Eyberg, S. M., Boggs, S. R., \& Algina, J. (2006). Predicting outcome in parent-child interaction therapy: Success and attrition. Behavior Modification, 30, 618-646. doi:10.1177/0145445504272977

Why Spanish Uses More Words Than English: an Analysis of Expansion and Contraction. (2021). Transfluent. Retrieved May 06, 2021, from https://www.transfluent.com/en/2015/07/why-spanish-uses-more-words-than-english-ananalysis-of-expansion-and-contraction/.

Yoshimasu K, Barbaresi WJ, Colligan RC, et al. Childhood ADHD is strongly associated with a broad range of psychiatric disorders during adolescence: a population-based birth cohort study. Journal of Child Psychology and Psychiatry. 2012;53(10):1036-1043. doi:

10.1111/j.1469-7610.2012.02567.x 